\title{
O campo térmico em episódio de inverno no bairro Bangu, Rio de Janeiro (RJ)
}

\section{The thermal field in winter episode in Bangu neighborhood, Rio de Janeiro (RJ)}

\author{
Lidiane de Oliveira Lemos ${ }^{* 1} \bowtie\left(\mathbb{D}\right.$, Antonio Carlos Oscar Júnior ${ }^{2} \bowtie(1)$ \\ 1Programa de Pós-Graduação em Geografia, Universidade do Estado do Rio de Janeiro, \\ Rio de Janeiro, RJ, Brasil \\ 2Instituto de Geografia, Departamento de Geografia Física, Universidade do Estado do \\ Rio de Janeiro, Rio de Janeiro, RJ, Brasil \\ *E-mail para correspondência: lidiane.o.lemos@gmail.com \\ E-mail: antonio.junior@uerj.br
}

Recebido (Received): 10/10/2020 Aceito (Accepted): 24/05/2021

Resumo: No âmbito dos estudos do clima urbano em ambientes tropicais, o campo térmico reveste-se de singular importância, afinal é diretamente influenciado pela complexidade de formas e funções, bem como impacta diretamente no conforto/desconforto térmico humano. Em face disto, o artigo buscou a compreensão da variabilidade térmica espacial no bairro Bangu, localizado na Zona Oeste do município do Rio de Janeiro (RJ). Para esse fim, três etapas metodológicas foram articuladas: reconhecimento das unidades da paisagem existentes no bairro a partir de técnica estatística de regionalização dos elementos físicos, biológicos e antrópicos; mapeamento da temperatura de superfície de inverno por imagens orbitais; e, realização de transectos móveis em intervalos de duas horas no dia 14/09/2018 para avaliação das condições in situ e potenciais de aquecimento e arrefecimento na escala do dia. Para o bairro Bangu foram identificadas 15 unidades de paisagem; as unidades com predominância de formas artificializadas, com intenso fluxo urbano, concentração de material particulado e funções associadas ao comércio, serviços e residencial manifestaram, sejam na coleta in situ ou via sensoriamento remoto, as maiores temperaturas intrabairro e os menores gradientes de arrefecimento. Em termos quantitativos, apresentou temperatura superficial superior à $30^{\circ} \mathrm{C}$, intensidade térmica de até $+8,8^{\circ} \mathrm{C}$ e gradiente térmico diário de até $5.6^{\circ} \mathrm{C}$. Já aquelas unidades com predomino de formas naturais, tais como as encostas vegetadas dos maciços locais, a temperatura superficial foi inferior a $26^{\circ} \mathrm{C}$ e o gradiente de térmico diário de até $10,6^{\circ} \mathrm{C}$, demonstrando a importância das formas naturais e funções ecossistêmicas para o campo térmico.

Palavras-chaves: Clima urbano; Modelo cartográfico; Gestão urbana.

Abstract: For urban climate studies in tropical context, the thermal field has singular importance, first because it is influenced by complexity of urban shapes and functions, as well as impact directly human comfort/discomfort. In view of this, the article aim to understand the spatial thermal variability in Bangu, located in the West Zone of the municipality of Rio de Janeiro (RJ). To this, three methodological steps were articulated: mapping landscape units using statistical techniques of regionalization considering physical, biological and anthropic elements; mapping winter surface temperature by orbital images; and, data collects by transects with two-hour intervals on 09/14/2018 to understand heating potential on the scale of the day. For Bangu, 15 landscape units were identified; in units with a predominance of artificial forms, intense urban flows, concentration of particulate matter and commercial, service and residential functions was observed the highest temperatures and the lowest cooling gradients. In quantitative terms, surface temperature was above $30^{\circ} \mathrm{C}$, thermal intensity up to $+8.8^{\circ} \mathrm{C}$ and daily thermal gradient up to $5,6^{\circ} \mathrm{C}$. The units with predominance of natural forms, such as vegetated slopes of the local massifs, the surface temperature was below $26^{\circ} \mathrm{C}$ and the daily thermal gradient was up to $10.6^{\circ} \mathrm{C}$, demonstrating the importance of natural forms and ecosystem functions for the thermal field.

Keywords: Urban climate; Cartographic model; Urban management. 


\section{Introdução}

A ação humana a partir do advento do capitalismo, enquanto conquistadora do espaço habitado, delineouse, habitualmente, na consideração sociedade e natureza como universos distintos. Esse antagonismo emergiu da modernidade a partir da percepção de ambiente ferido.

A cidade é o lugar da mais efetiva interação homem-natureza (MONTEIRO; MENDONÇA, 2015). "No começo era a natureza selvagem, composta por formas naturais, que ao longo da história vão sendo substituídas por objetos fabricados, técnicos, mecanizados e depois cibernéticos (...)” (SANTOS, 1997). Edificam-se, assim, um conjunto de paisagens constituídas por formas indissociáveis, solidárias e contraditórias, regidas por sistemas de ações (SANTOS, 1997). Dessa maneira, sociedade e natureza (agora artificializada) não podem mais serem vistas como oposição, mas sim como integração.

As modificações introduzidas pela nova realidade urbana tornam-se tanto mais predatória quanto mais as relações de produção evolui (MONTEIRO; MENDONÇA, 2015). Consequentemente, um clima específico (clima urbano) é constituído sobre a atmosfera local, advindo da transformação do balanço de energia, segundo um jogo holístico entre ar atmosférico e as formas urbanas (física, biológico e artificial) materializadas (MONTEIRO, 1976).

Algumas evidências do clima urbano são observadas na configuração das ilhas de calor (ICs), cujas temperaturas da superfície e do ar expressam-se mais elevadas que as áreas circundantes. Dentre as formas urbanas responsáveis pela configuração das ilhas térmicas, Pazera Júnior (1976), Danni-Oliveira (1995), Brandão (1996), Pinho e Orgaz (2000), Gartland (2010) e Amorim (2015) destacaram:

- a topografia do sítio;

- retirada da cobertura vegetal e redução de massa líquida provocando maior estoque de calor sensível e redução do fluxo de calor latente (evapotranspiração);

- as propriedades térmicas dos materiais construtivos (menor calor específico e maior capacidade térmica), como o cimento, tijolo e asfalto, que possibilitam maior absorção e armazenamento de ondas curtas, além de apresentarem grande condutância;

- arranjo geométrico dos prédios e sua verticalidade. A massa aglomerada de edifícios funciona como reservatório de energia proporcionando reflexões múltiplas entre eles e convertendo-se em obstáculo para as correntes de ventos. Dificultando, assim, a dispersão do calor;

- a produção artificial de calor expressa pelas funções antrópicas (circulação de veículos, processos industriais e aparelhos de ares condicionados);

No Brasil, os estudos do clima urbano com viés geográfico, ganham vulto a partir da obra do professor Monteiro (1976), cujos pressupostos teórico-metodológicos foram incorporados por Brandão à análise do complexo clima urbano da cidade do Rio de Janeiro. Sua pesquisa impulsionou investigações pelos bairros cariocas. Cabe nesta revisão voltar-se apenas ao campo térmico: Méier (FRANÇA; BRANDÃO, 2000), Copacabana (MALHEIROS; BRANDÃO, 2000), Bangu (LUCENA; BRANDÃO, 2000; LUCENA, 2002), Centro (BRANDÃO; LUCENA, 2000), Maracanã (FARIAS; BRANDÃO, 2006), Penha (PEREIRA; BRANDÃO, 2008) e Ilha do Fundão (OSCAR JÚNIOR; BRANDÃO, 2015).

O bairro Bangu apresenta a fama de ser o mais quente do município. Ademais, as intervenções urbanísticas do projeto Rio Cidade II (2000/2002) não consideraram sua realidade climática e a instalação do sistema de climatização do centro comercial segue sem as devidas manutenções. Desta maneira, torna-se imperativo a compreensão espacial do campo térmico em Bangu como subsídio as políticas públicas de ordenamento e planejamento territorial adequados à realidade climática do bairro.

Esta pesquisa objetivou analisar a relação entre as formas físicas, biológicas e antrópicas e o comportamento térmico do bairro Bangu, situado na Zona Oeste (ZO) do município do Rio de Janeiro, em episódios de inverno. Tendo como objetivos específicos: investigar o padrão térmico e integrar os dados de superfície as observações in situ.

\section{Material e método}

\section{1. Área de estudo}

De latitude $22^{\circ} 52^{\prime} 24^{\prime}$ 'S e longitude $43^{\circ} 27^{\prime} 18^{\prime}$ W, Bangu encontra-se localizado na Zona Oeste do Município Rio de Janeiro (Figura 1), fazendo vizinhança com os bairros Gericinó, Padre Miguel, Realengo, Santíssimo, Senador Camará e Campo Grande, além dos municípios de Nova Iguaçu, Mesquita e Nilópolis. 
Em seus aproximadamente $37,44 \mathrm{~km}^{2}$, distribui-se uma população absoluta de 243.125 habitantes (Instituto Brasileiro de Geografia e Estatística - IBGE, 2010).

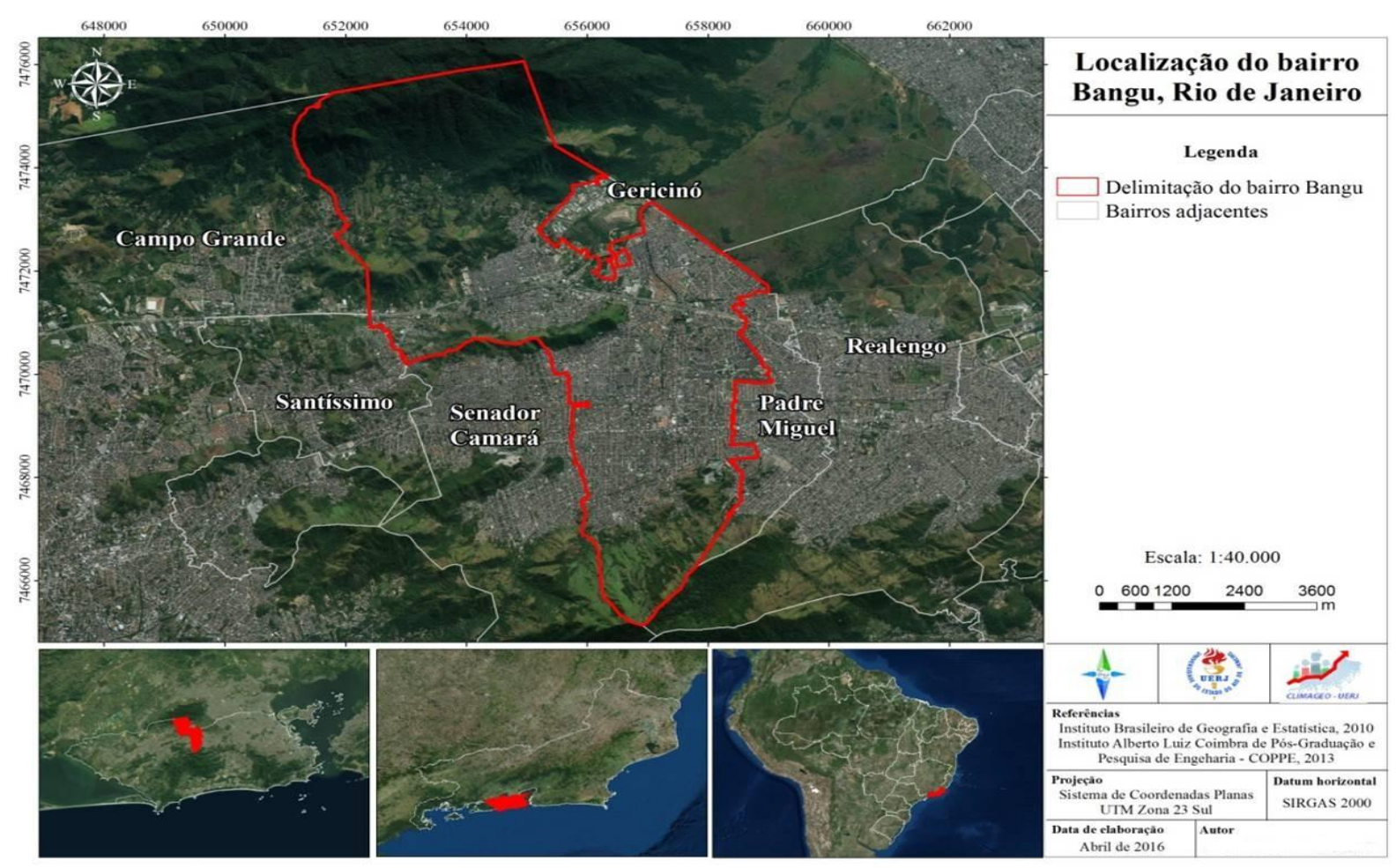

Figura 1: Localização do bairro Bangu, Rio de Janeiro. Fonte: IBGE (2010); Prefeitura do RJ (2013).

O sítio topográfico ao qual o bairro está assentado esboça-se determinante no quadro climático local, conferindo suscetibilidade a elevadas temperaturas. Estrangulada entre os maciços Gericinó-Mendanha e Pedra Branca, a baixada de Bangu, apresenta uma dinâmica de circulação atmosférica marcada pela formação dos ventos anabáticos/catabáticos e o efeito Föhn (Figura 2).

Os sistemas de ventos anabáticos e catabáticos desenvolvem-se devido às grandes oscilações no relevo, como o presente no espaço banguense, e são de origem térmica, regidos pela variação do aquecimento solar. Durante o dia, as vertentes das montanhas ao receberem maior exposição à radiação são mais aquecidas do que o fundo do vale, determinando gradiente relativamente fraco e direcionando o vento vertente acima ventos anabáticos ou de vale. Já os ventos catabáticos ou de montanha, ocorrem devido ao esfriamento mais rápido das vertentes à noite, invertendo o gradiente de pressão e fazendo, portanto, o ar frio e denso deslocarse em sentido ao vale (AYOADE, 1996).

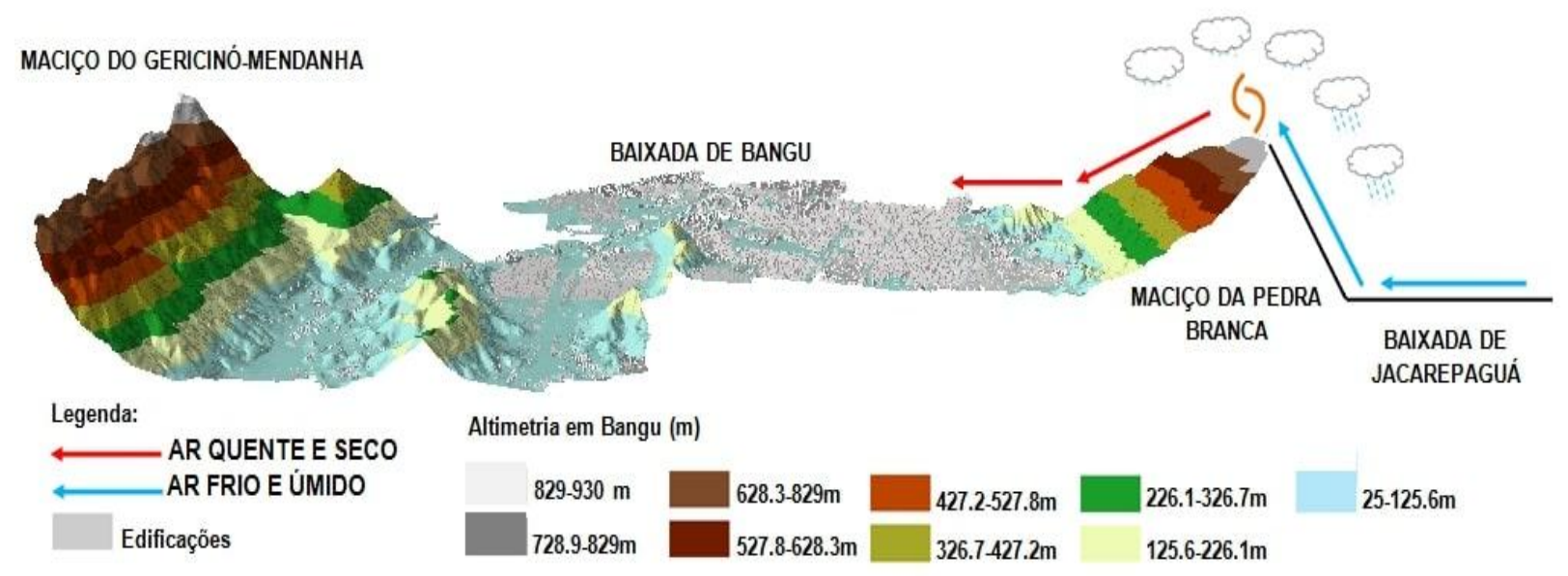

Figura 2: Efeito Fohn no bairro Bangu. Fonte: Autor (2020). 
Os Föhns são sistemas de ventos de importância terciária, causados pela topografia, com ou sem variação no aquecimento solar. Esses ventos secos e quentes se desenvolvem a sotavento de uma cadeia montanhosa quando o ar estável é forçado a ultrapassá-la (AYOADE, 1996). Desta forma, os ventos úmidos vindos do Oceano Atlântico que sopram a barlavento, na vertente sul do maciço da Pedra Branca, encontram neste uma barreira orográfica. Após transpor o maciço montanhoso, a sotavento, o vento desce quente, devido aos processos adiabáticos, além de seco e com baixa mobilidade na baixada de Bangu; os maciços GericinoMendanha e Pedra Branca aprisionam as massas de ar e dificultam sua circulação. Assim, o bairro Bangu transforma-se em um "bolsão de calor" (LUCENA, 2002).

\subsection{Procedimentos metodológicos}

A metodologia foi estruturada em torno de procedimentos teóricos e práticos que buscaram a compreensão da relação das formas físicas, biológicas e antrópicas no arranjo espacial do campo térmico no bairro Bangu. Parte-se, para tanto, da proposta metodológica de Monteiro (1976; 1990), Brandão (1996) e Bertrand (2004) para a consolidação das três etapas do processo metodológico: 1) identificação das unidades da paisagem (UPs); 2) cálculo e mapeamento da temperatura de superfície terrestre (TST); e, 3) mensuração da temperatura por transectos móveis, a cada duas horas, para compreensão da repercussão das formas e funções nas taxas de aquecimento e arrefecimento.

A primeira etapa encontra-se embasada na identificação das unidades da paisagem do bairro por meio da integração das formas urbanas (físicas, biológicas e antrópicas), visando confrontar as mesmas com o campo térmico. Para a compreensão espacial desse campo térmico, foram aplicadas técnicas de sensoriamento remoto, partindo de oito imagens de inverno LANDSAT-8 que possibilitaram o mapeamento e análise panorâmica da TST. A opção pelo inverno se fundamenta na obra de Monteiro (1976), justificando que a condição atmosférica mais seca dessa estação, propicia menor cobertura de nuvens e concentração de poluente. Adicionalmente, o vapor d'água, um dos maiores absorvedores da radiação emitida pela superfície na faixa do infravermelho termal, no período de inverno, tem menor potencial de interferência na resposta radiométrica dos alvos.

Ademais, a identificação das UPs subsidiou a escolha da implantação dos pontos para a coleta in situ durante o experimento de campo. Esses dados foram coletados em intervalos horários no dia 14/09/2018.

\subsubsection{Identificação das Unidades da Paisagem (UPS)}

Considerando a proposta teórico-metodológica de Bertrand (2004), que identifica na unidade de paisagem geossistêmica a paisagem total por integrar todos os elementos essenciais, ou seja, elementos físicos, biológicos e antrópicos, propõem-se aqui uma síntese com tais características do bairro. Esta síntese é responsável pelo reconhecimento de unidades que contém particularidade quanto à relação dos elementos físicos, biológicos e antrópicos e, consequentemente, mantém influencia sobre o campo térmico.

Alguns indicadores foram escolhidos para o modelo cartográfico, a saber: NDVI, orientação da encosta, uso e cobertura do solo, temperatura da superfície e altura das edificações. A importância de se observar o NDVI está na relevância da evapotranspiração como regulador térmico. A orientação das vertentes fornece um indicativo de exposição à radiação solar. A cobertura e o uso do solo interferem na emissividade do comprimento de onda. Já a temperatura da superfície ajuda a compreender a distribuição das fontes de calor intraurbano que podem levam a formação da ICs. Por fim, a altura da edificação, interfere na radiação de ondas longas e nas condições de ventilação, aumentando o estoque de calor sensível.

O NDVI foi obtido pela razão entre a diferença e a soma das refletâncias das bandas 5 e 4 do OLI LANDSAT-8, de 31/01/2016, já contendo calibrações atmosféricas da USGS. A fórmula foi aplicada conforme proposto por Rouse et at. (1973) (Equação 1). Esse índice varia de -1 a 1, expressando a saúde da vegetação. Quanto mais próximo do 1 mais saudável se encontra a cobertura vegetal e quanto mais próximo do -1 maior é o estresse hídrico ou presença de áreas construídas, indícios de solos descobertos e rochas.

$$
N D V I=\text { Float }(N I R-R E D) / \text { Float }(N I R+R E D)
$$

Para gerar a orientação da encosta, a ferramenta "Aspect" foi acionada utilizando como dado de entrada a imagem SRTM de resolução espacial de 30 metros da USGS, sendo calculada em graus. Sequencialmente, a categorização dos atributos dos shapefiles por classes de uso e cobertura do solo (2016) e das alturas das edificações (2018) originaram a espacialização das informações. Os mesmos foram obtidos junto a Prefeitura 
do Rio de Janeiro/Sistema Municipal de Informações Urbanas - SIURB. Já a termografia da superfície terrestre foi calculada a partir da banda 10 da imagem LANDSAT-8, representativa do infravermelho termal, de 31/01/2016, contendo correções pela USGS. Com a ativação do complemento Land Surface do software Qgis, a transformação dos valores digitais dos níveis de cinzas da imagem para radiância e, consequentemente, para temperatura $\mathrm{K} \mathrm{e}{ }^{\circ} \mathrm{C}$ ocorrem automaticamente.

Com a elaboração de todas as informações ambientais recorreu-se a técnica skater de regionalização do software TerraView. O modelo cartográfico resultante possibilitou o reconhecimento de unidades da paisagem intrabairro, com suas singularidades de formas físicas, biológicas e antrópicas, para a confrontação com o campo térmico superficial e in situ. Ademais, o reconhecimento das UPs foi essencial, pois conduziram a decisão da implantação dos pontos de mensurações durante o experimento de campo, possibilitando “adentrar o bairro para tomar-lhe a temperatura” (MONTEIRO, 1976; 1990).

\subsubsection{Cálculo da Temperatura da Superfície Terrestre (TST)}

A estimativa da temperatura da superfície terrestre encontra-se ancorada na seleção e processamento de dados do sensor Thermal Infrared Sensor (TIRS). Oito imagens banda 10 (02/08/2013, 21/08/2014, 26/08/2016, 14/09/2017, 29/06/2018, 15/07/2018, 01/09/2018, 02/07/2019), referentes ao inverno, foram adquiridas no site do United States Geological Survey (USGS). Para o cálculo da TST cumpriu-se a sequencia das equações apresentadas no fluxograma (Figura 3): 1) inserções das bandas 10 do LANDSAT-8 no software Arcgis; 2) conversão dos números digitais (DNs) para radiâncias da banda 10; 3) conversão dos DNs para reflectância e correção da reflectância das bandas 4 e 5, do sensor OLI LANDSAT-8; 4) cálculo do índice de vegetação por diferença normalizada (NDVI), a partir das reflectâncias corrigidas das bandas 4 e 5; 5) estimativa da emissividade; 6) correção atmosférica; 7) conversão da radiância para TST e 8) conversão TST em Kelvin (K) em graus Celsius $\left({ }^{\circ} \mathrm{C}\right)$.

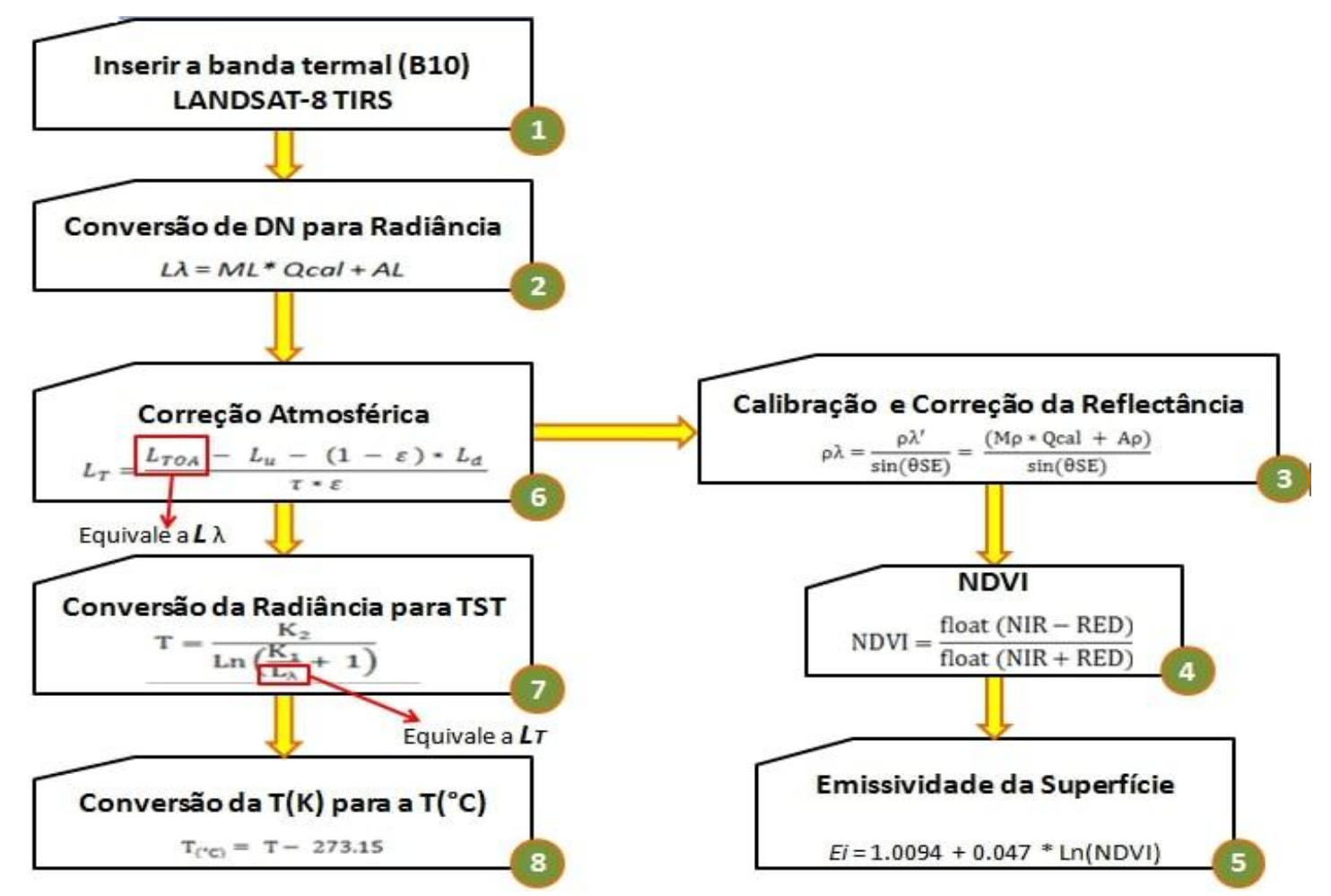

Figura 3: Fluxograma das equações empregadas para o cálculo da TST.

O fator multiplicativo de redimensionamento (ML), fator de redimensionamento aditivo específico (AL), constante de calibração $1(\mathrm{k} 1)$, constante de calibração $2(\mathrm{k} 2)$, fator de redimensionamento multiplicativo $(\mathrm{M} \rho)$, fator de redimensionamento aditivo (A $\rho)$ e ângulo de elevação do sol local ( $\theta$ SE) inseridos nas fórmulas foram extraídos dos metadados de cada imagem. Os valores quantizados calibrados pelos pixels em DN (Qcal) são as próprias bandas 4, 5 e 10, em suas respectivas equações de calibração. Já a transmitância do ar $(\tau)$, radiância emitida $(\mathrm{L} u)$ e recebida $(\mathrm{L} d)$ pela superfície são parâmetros corretivo da atmosfera e do processo de interação radiação-atmosfera-superfície e foram obtidos através da Calculadora de Parâmetros de Correção Atmosférica que incorpora dados específicos de data, hora e local do satélite e das condições de 
superfície: altitude $(\mathrm{Km})$, temperatura $\left({ }^{\circ} \mathrm{C}\right)$, pressão $(\mathrm{mb})$ e umidade relativa do ar $(\%)$. O acesso à ferramenta ocorreu pela página da NASA/GSFC (https://atmcorr.gsfc.nasa.gov/) e os dados meteorológicos foram adquiridos do Instituto Nacional de Meteorologia (INMET), tendo a Estação do Forte de Copacabana como referência.

Para o reconhecimento da emissividade específica seguiu-se o método de estimava de Zhang et al. (2006), que além de adotar Van de Griend; Owe (1993) engloba classes mais detalhadas de NDVI (Tabela 1). Ressalta-se que a correção atmosférica está embasada em Barsi et al. (2003); (2005). As demais equações seguiram o estabelecido pela USGS quanto ao uso dos produtos LANDSAT-8.

Tabela 1: Estimativa da emissividade usando o NDVI

\begin{tabular}{ll}
\hline NDVI & Emissividade de superfície (Ei) \\
\hline NDVI $<-0.185$ & 0.995 \\
$-0.185 \leq$ NDVI $<0.157$ & 0.970 \\
$0.157 \leq$ NDVI $\leq 0.727$ & $1.0094+0.047 \ln (\mathrm{NDVI})$ \\
NDVI $>0.727$ & 0.990 \\
\hline
\end{tabular}

\subsubsection{Experimento de campo}

O experimento de campo, no dia 14/09/2018, foi realizado para complementar a compreensão do campo térmico e contou com a distribuição de 14 pontos amostrais. Adotou-se a técnica do transecto móvel (HASENACK; BECKE, 1986 apud BRANDÃO, 1996) com dois carros partindo da estação de trem Bangu e seguindo em sentidos opostos: centro-norte e sentido centro-sul. O transeto centro-norte abarcou 5 pontos amostrais (pontos 1 a 5), enquanto o centro-sul 9 (pontos 6 a 14).

Foram feitas medições às $9,11,13,15$ e 17 horas referentes à temperatura do ar, umidade relativa, velocidade e direção do vento, nebulosidade, índice de fumaça, quantidade de veículo e pedestre por minutos. Lamentavelmente, devido à instabilidade atmosférica, provocada pelo avanço do sistema frontal na cidade do Rio de Janeiro, não foi possível realizar medições às 19 e 21 horas impossibilitando a sondagem da liberação de energia noturna, como o previsto. Cada transecto teve a duração máxima de 60 minutos.

Os resultados do campo foram tabelados em planilha Excel (2007) e com os valores de temperatura e umidade foram gerados mapeamentos temáticos do campo térmico. Trabalhou-se com as subtrações de temperaturas de cada ponto em relação ao ponto de menor registro horário de temperatura. Buscando uma abordagem comparativa, tomou-se como arcabouço a classificação proposta por Brandão (1996) de intensidade da ilha de calor na cidade do Rio de Janeiro: fraca $\left(0,1-2,0^{\circ} \mathrm{C}\right)$; moderada $\left(2,1-4,0^{\circ} \mathrm{C}\right)$; forte $\left(4,1-6,0^{\circ} \mathrm{C}\right)$ e muito forte (Superior a $6,1^{\circ} \mathrm{C}$ ). Bem como, analisou-se o comportamento de cada ponto amostral ao logo do dia (taxas de aquecimento e resfriamento).

\section{Resultados e discussões}

\subsection{As Unidades da Paisagem (UPS)}

A síntese cartográfica possibilitou o reconhecimento de 15 unidades da paisagem em Bangu (Figura 4), diferenciadas quanto à relação das características físicas (temperatura de superfície e orientação da encosta), biológica (NDVI) e antrópicas (cobertura e uso do solo e altura das edificações). Portanto, cada unidade deve expressar particularidades quanto à influência dos elementos climáticos, refletindo distintos topoclimas.

Como as unidades da paisagem também serviram de alicerce para a escolha dos pontos amostrais para o experimento de campo, apresenta-se nesta pesquisa, apenas a descrição das unidades da paisagem que subsidiaram o campo. Contudo, não deixando de analisar a inter-relação das formas contidas nas demais UP e sua influência sobre TST.

Para a seleção das UP do experimento de campo, algumas ponderações foram levantadas, como os objetivos propostos, limitações técnicas e questões de segurança. Sendo, assim, a UP1, UP14 (localizadas no maciço do Gericinó-Mendanha), UP3, UP6, UP7 (no maciço da Pedra Banca), UP10, UP15 (favela da Vila Kennedy), UP2, UP8, UP9 e UP12 ficaram de fora da sondagem. Logo, apenas as UP4, UP5 UP11 e UP13, conduziram a investigação topoclimática do comportamento térmico. As características predominantes da UP4, UP5 UP11 e UP13 são apresentadas na Figura 5.

Na UP13 distribuiu-se 11 pontos amostrais (pontos 1, 2, 3, 4, 6, 7, 8, 10, 12, 13 e 14) (Figura 6 e 7). Pois, tal unidade demonstrou-se extensiva e conforme afirma Monteiro (1990), forçosamente por mais 
homogênea que ela seja, conterá uma pluralidade microclimática. Diferentemente, as UP4, UP5 e UP11 por serem menores e garantirem a persistência de uma única condição tiveram 1 ponto amostral em cada: respectivamente os pontos 9, 5 e 11 (Figura 6 e 7).

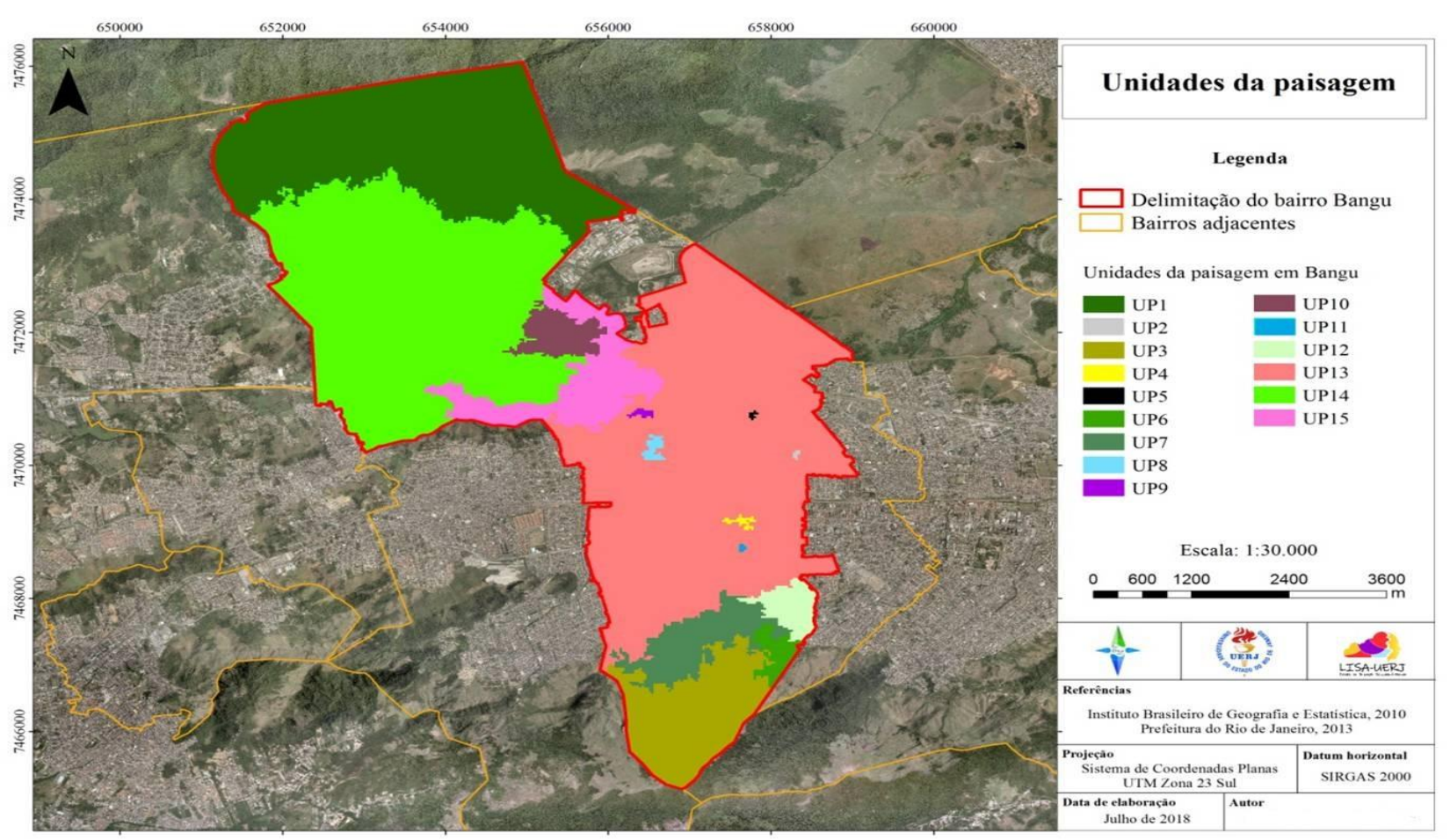

Figura 4: Unidades da paisagem em Bangu. Fonte: IBGE (2010); Prefeitura do RJ (2013).

\begin{tabular}{|c|c|c|c|c|c|}
\hline & NDVI & Uso e cobertura & Edificação & Temperatura & Orientação \\
\hline UP4 & $\begin{array}{c}\text { Vegetação não saudável } \\
(67,5 \%) \\
\begin{array}{c}\text { Vegetação morta ou objeto } \\
\text { inanimado }(32,5 \%)\end{array}\end{array}$ & $\begin{array}{c}\text { Areas de comércio e serviços } \\
(46,36 \%) \\
\text { Areas residenciais }(41,29 \%) \\
\text { Areas institucionais e de } \\
\text { infraestrutura pública }(12,35 \%)\end{array}$ & $\begin{array}{c}\text { Variação de altura: } \\
0-19,66 \mathrm{~m} \\
\\
\text { Média de altura: } \\
7,62\end{array}$ & $\begin{array}{c}27,6-28,1^{\circ} \mathrm{C} \\
(95 \%)\end{array}$ & $\begin{array}{c}\text { Norte } \\
(37,83 \%)\end{array}$ \\
\hline UP5 & $\begin{array}{l}\text { Vegetação não saudável } \\
(\$ 1,82 \%) \\
\text { Vegetação morta ou objeto } \\
\text { imanimado }(18,18 \%)\end{array}$ & Areas residenciais $(100 \%)$ & $\begin{array}{c}\text { Variação de altura: } \\
2,32-19,53 \mathrm{~m} \\
\text { Média de altura: } \\
6,45\end{array}$ & $\begin{array}{c}27-27,6^{\circ} \mathrm{C} \\
(54,55 \%)\end{array}$ & $\begin{array}{l}\text { Noroeste } \\
(65,56 \%)\end{array}$ \\
\hline UP11 & $\begin{array}{c}\text { Vegetação não saudável } \\
(60 \%) \\
\begin{array}{l}\text { Vegetação morta ou objeto } \\
\text { imanimado }(40 \%)\end{array}\end{array}$ & $\begin{array}{c}\text { Areas residenciais }(76,95 \%) \\
\text { Cobertura arbórea e arbustiva } \\
(23,05 \%)\end{array}$ & $\begin{array}{c}\text { Variação de altura: } \\
0-17,14 \mathrm{~m} \\
\text { Média de altura: } \\
6,94\end{array}$ & $\begin{array}{c}27,6-28,1^{\circ} \mathrm{C} \\
(90 \%)\end{array}$ & $\begin{array}{l}\text { Nordeste } \\
(49,03 \%)\end{array}$ \\
\hline UP13 & $\begin{array}{c}\text { Vegetação não saudável } \\
(72 \%) \\
\text { Vegetação moderadamente } \\
\text { saudável }(4,57 \%) \\
\text { Vegetação morta ou objeto } \\
\text { inanimado }(23,43 \%)\end{array}$ & $\begin{array}{c}\text { Areas residenciais }(76,59 \%) \\
\text { Favela }(6,52 \%) \\
\text { Areas de comércio e serviços } \\
(3,8 \%)\end{array}$ & $\begin{array}{c}\text { Variação de altura: } \\
0-33,1 \mathrm{~m} \\
\text { Média de altura: } \\
6 \mathrm{~m}\end{array}$ & $\begin{array}{c}28,1-28,6^{\circ} \mathrm{C} \\
(22,10 \%)\end{array}$ & $\begin{array}{c}\text { Norte } \\
(16,31 \%)\end{array}$ \\
\hline
\end{tabular}

Figura 5: Características das unidades da paisagem em Bangu. Organização: Autor (2018) 


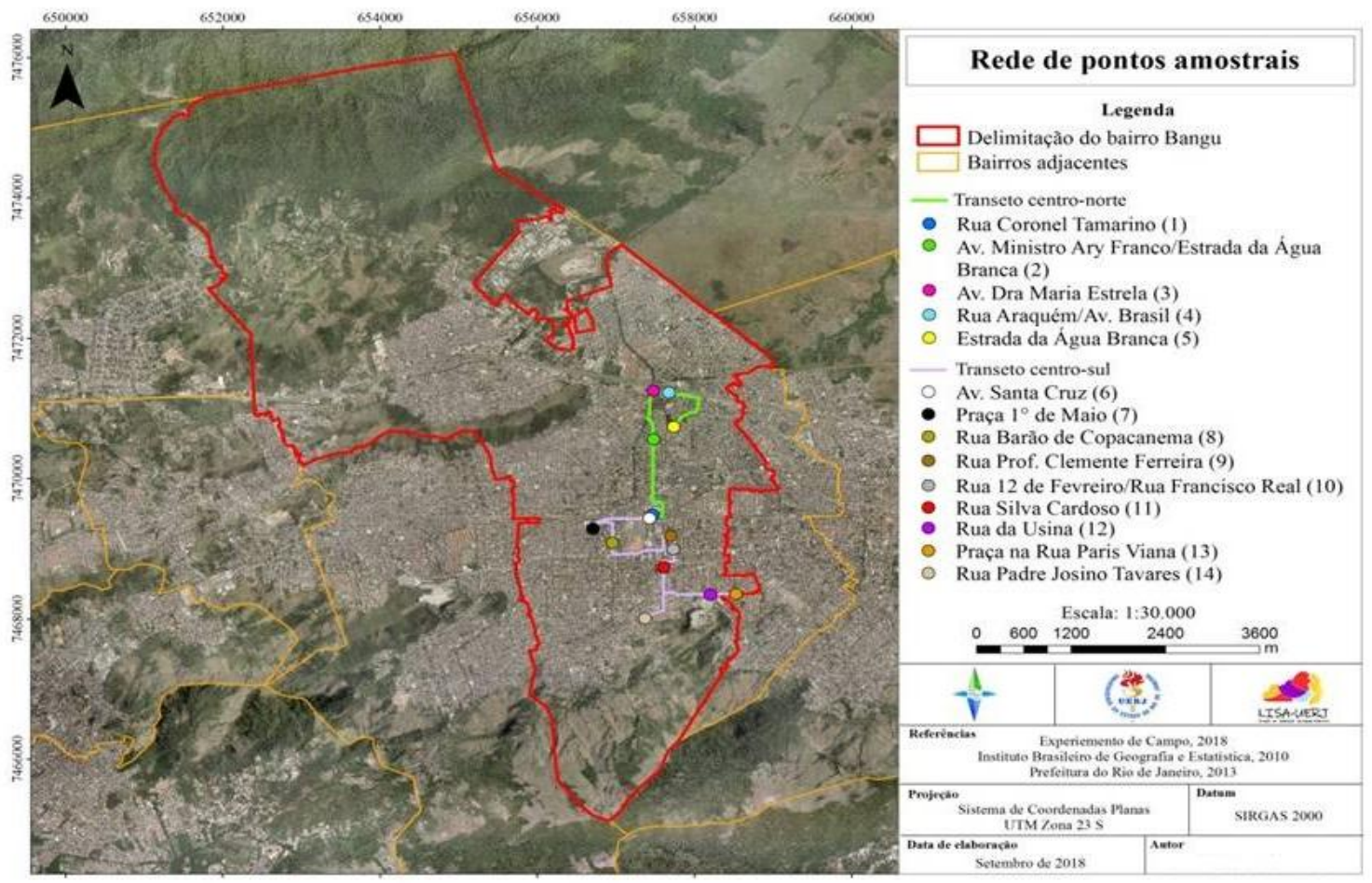

Figura 6: Localização dos pontos de medidas. Fonte: IBGE (2010), Prefeitura do RJ (2013); Autor (2018).

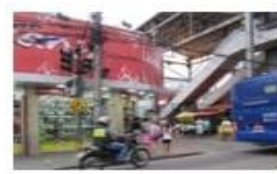

P1

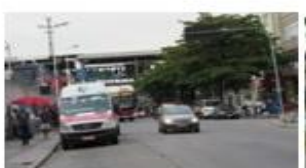

P6

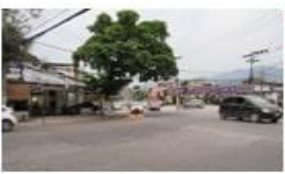

P2

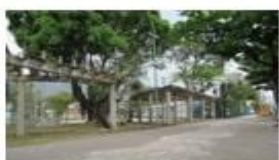

P7

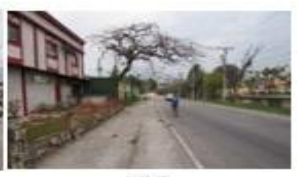

P3

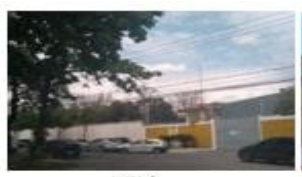

P4

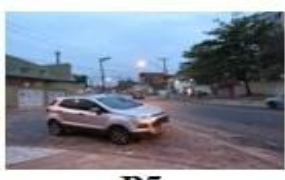

P5

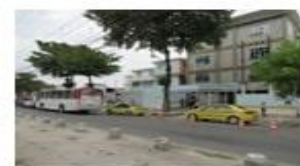

P11

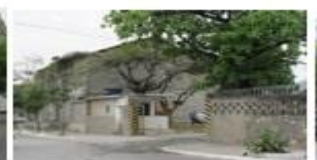

P12

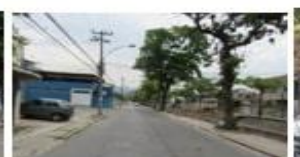

P8

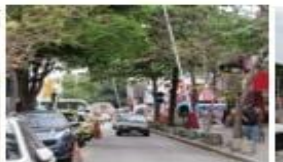

P9

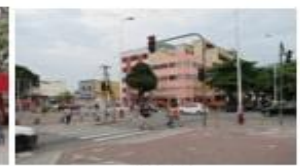

P10

Figura 7: Visualizações dos pontos amostrais distribuídos entre as UP. Fonte: Experimento de Campo (2018).

\subsection{Estimativa da Temperatura da Superficie Terrestre (TST)}

A TST (Figura 8) possibilitou a compreensão da relação das diferentes unidades da paisagem (com suas particularidades física, biológica e antrópica) com a radiação emitida pela superfície em todo o espaço do bairro, tendo em vista a ampla visualização proporcionada pelas imagens orbitais. A análise do campo térmico, no episódio sazonal de inverno, indica a predominância das faixas de temperatura superficiais mais altas $\left(>30^{\circ} \mathrm{C}\right)$, sendo que apenas uma pequena porção do território apresenta faixas mais amenas de temperatura (menor que $26^{\circ} \mathrm{C}$ ). Isso se explica pela predominância das formas artificializadas, associada aos usos de comércio e serviço, em detrimento das formas naturais, reguladora da variabilidade térmica. 


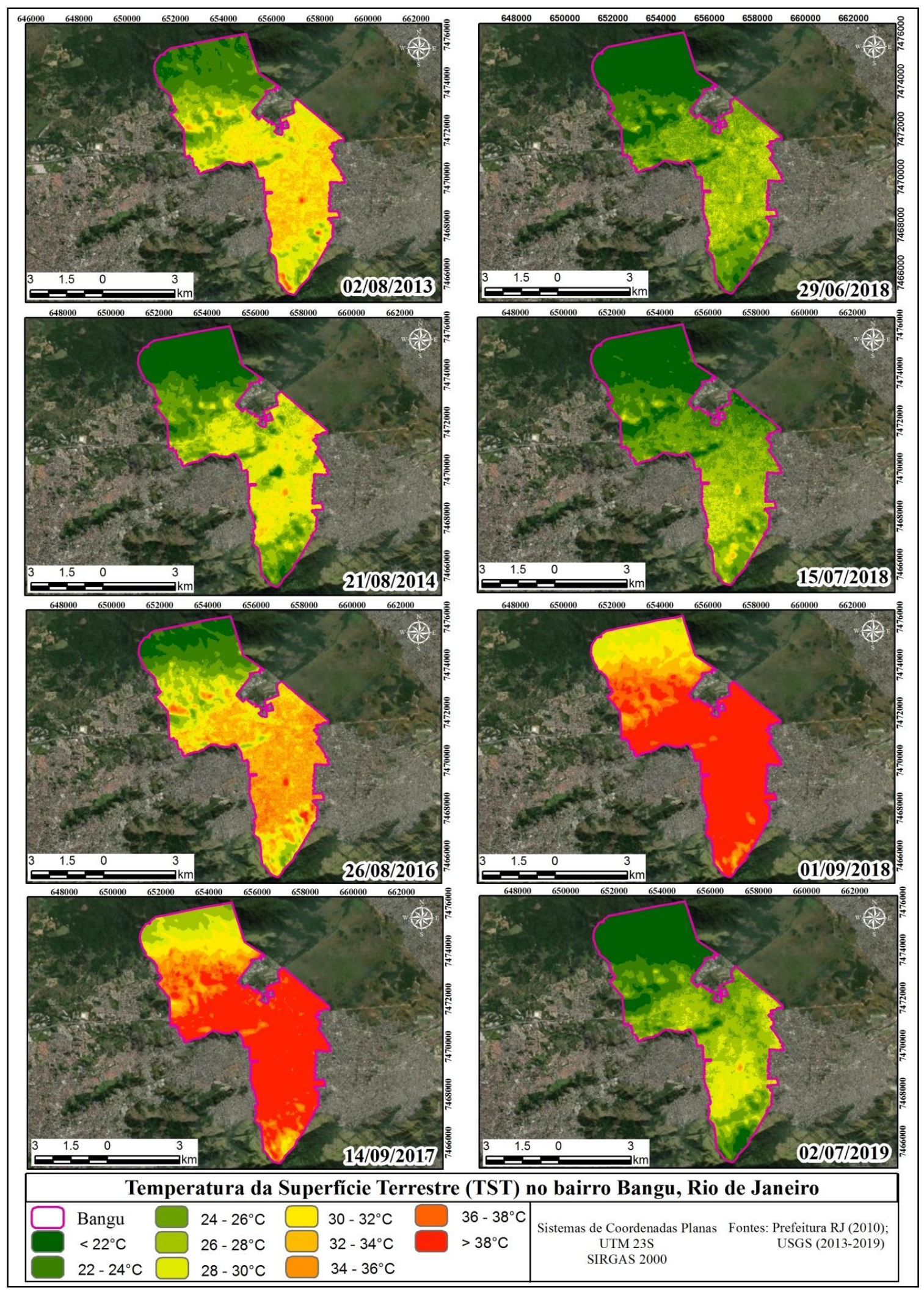

Figura 8: TST em Bangu. Fonte: Prefeitura do RJ (2013); USGS (2013-2019).

No geral, as TSTs elevadas $\left(>30^{\circ} \mathrm{C}\right)$ estiveram presentes nas unidades de paisagem com áreas pavimentadas e/ou edificadas e predominância de vegetação não saudável (UP2, UP4, UP5, UP7, UP8, UP9, UP10, UP11, UP12 e UP13). As mais amenas $\left(<28^{\circ} \mathrm{C}\right)$, relacionadas às áreas de vegetação das encostas dos maciços da Pedra Branca e, sobretudo, Gericinó-Mendanha (UP1, UP3, UP6, UP14 e UP15) devido a maior conservação e o efeito das brisas. No que se refere às unidades da paisagem investigadas no experimento de campo (UP4, UP5, UP11 e UP13) é possível localizar e descriminar praças e espaços com arborização cujas temperaturas se manifestaram mais baixas que aqueles espaços densamente construídos e artificializados. Isso evidencia, sobretudo, a importância da evapotranspiração na regulação térmica intraurbana. 
No mais, a variabilidade térmica da TST nas UP investigadas em campo seguiu o seguinte padrão: a) Na UP13 a TST predominante variou entre 30 a $38^{\circ} \mathrm{C}$, com destaque para o shopping (centro da UP), cuja propriedade refletiva do telhado conferiu elevadas TSTs. A UP13 apresenta, predominantemente, vegetação não saudável, uso e cobertura relacionados ao residencial, favela e comércio e serviços, presença de edificações com altura média de $6 \mathrm{~m}$ e encostas voltadas para o norte; razão para a elevada TST; b) A UP4 e UP5 apresentou, sobretudo, TST entre $24^{\circ} \mathrm{C}$ e $32^{\circ} \mathrm{C}$; c) a UP11 com presença, sobretudo, de vegetação não saudável, áreas residenciais e de comércio e serviços, média de altura das edificações de 7,62 m e encostas voltadas para o norte, apresenta TST em destaque entre $24^{\circ} \mathrm{C}$ e $28^{\circ} \mathrm{C}$. Apesar de suas características a UP11 é a única dentre as investigadas que possui $23 \%$ de cobertura arbórea arbustiva.

\subsection{Experimento sazonal de inverno}

Complementando a análise da TST, o experimento de campo com levantamentos in situ, possibilitando melhor entendimento do mapeamento térmico e ritmo diário de variabilidade da temperatura e fluxos de calor. O campo térmico às 9 horas da manhã apresentou um gradiente norte-sul (Figura 9). Os pontos quentes na área de comércios e serviços do bairro alcançaram uma intensidade de $4,8^{\circ} \mathrm{C}$, como na Rua Doze de Fevereiro/Francisco Real (Ponto 10 - UP13), o que pode ser explicado pela situação de calmaria e o intenso fluxo de veículos responsáveis pela liberação de poluentes, típico do horário matutino, com intensa circulação de pessoas para atividades laborais e escolares. Contudo, foi na área residencial, na Rua Padre Josino Tavares (Ponto 14 - UP13), que se configurou o núcleo de maior intensidade: $5,2^{\circ} \mathrm{C}$. Possivelmente, a chegada de particulados advindo da pedreira instalada na Rua da Usina, trazidos pelos ventos de NE, pode ser um fator explicativo. Já o ponto fresco se expressou na Praça $1^{\circ}$ de Maio, espaço arborizado (Ponto 7 UP13).

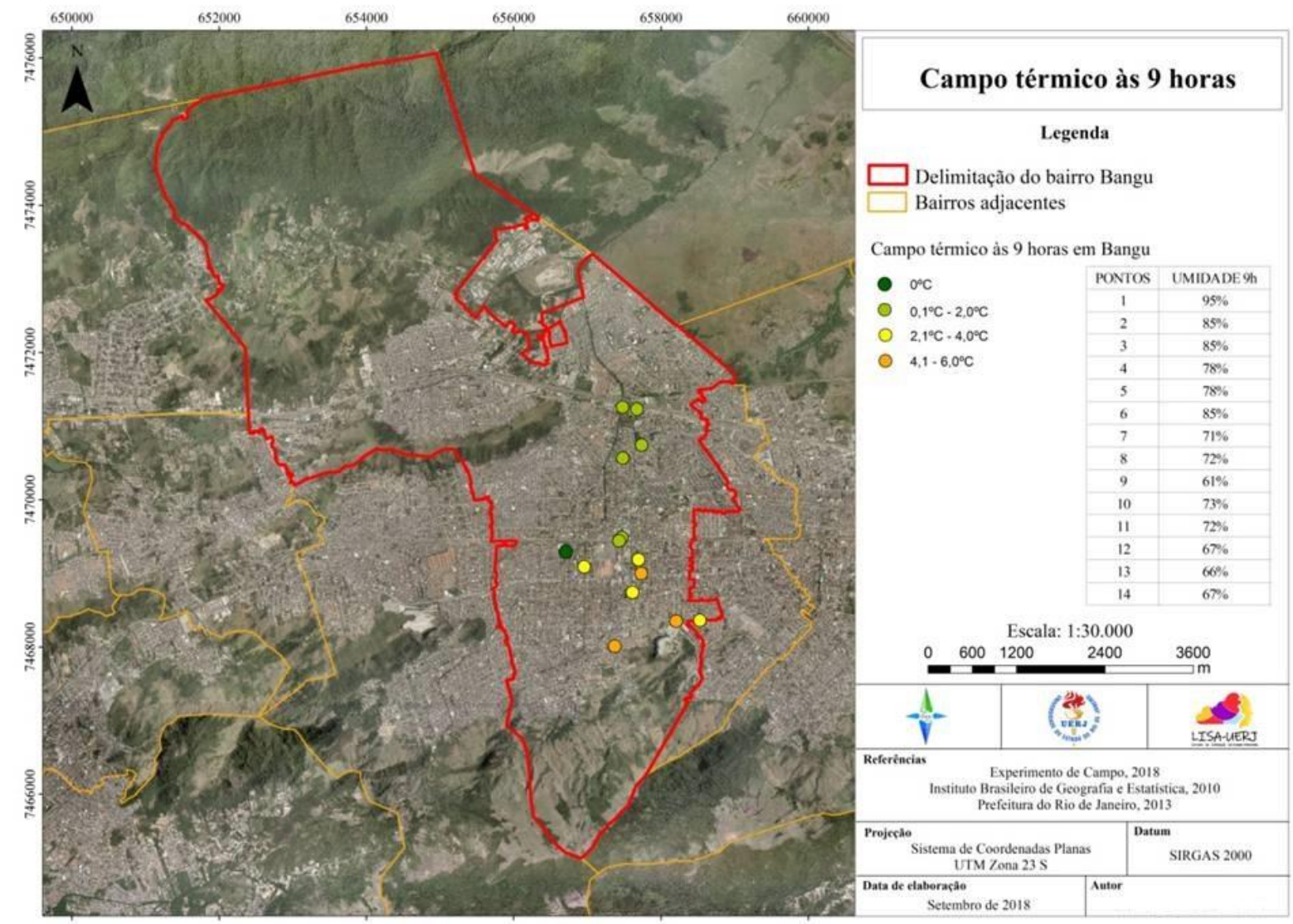

Figura 9: Campo térmico às 9 horas. Fonte: IBGE (2010); Prefeitura do RJ (2013); Experimento de Campo (2018).

Às 11 horas (Figura 10), a área comercial e de serviços do bairro transformou-se em uma cúpula de calor com os principais logradouros ultrapassando $6,1^{\circ} \mathrm{C}$, como a Rua Coronel Tamarino (Ponto 1 - UP13), Av. Santa Cruz (Ponto 6 - UP13), Rua Barão de Copacanema (Ponto 8 - UP13), Rua Prof. Clemente Ferreira (Ponto 9 - UP4) e Silva Cardoso (Ponto 11- UP11). Para estes pontos amostrais, com exceção da Barão de Copacanema (Ponto 8), o horário das 11 horas indicou a menor umidade relativa do dia. A área residencial 
não só manteve os espaços mais quentes como intensificou seu núcleo, registrando valores também acima de $6,1^{\circ} \mathrm{C}$. Em consonância com o primeiro horário, a Rua Padre Josino Tavares (Ponto 14 - UP13) destacou-se com intensidade de $8,8^{\circ} \mathrm{C}$ (muito forte magnitude). Opondo-se ao referido logradouro, a Av. Ministro Ary Franco/Estrada da Água Branca (Ponto 2 - UP13) esboçou o núcleo fresco.

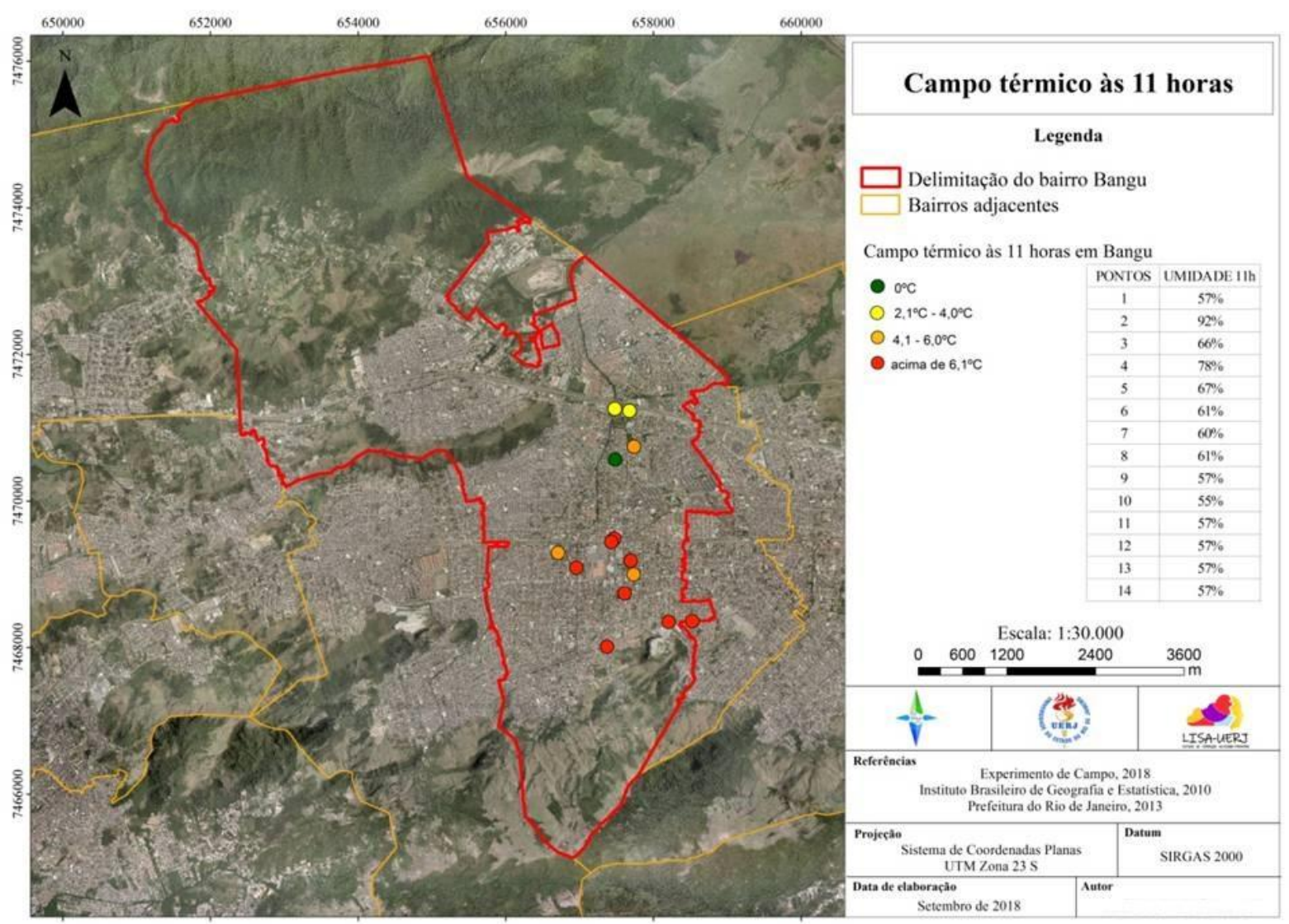

Figura 10: Campo térmico às 11 horas. Fonte: IBGE, 2010; Prefeitura do RJ (2013); Experimento de Campo (2018).

O campo térmico das 13 (Figura 11) e 15 horas convergiram ao apresentarem um aumento da carga térmica em direção ao espaço comercial e de serviços do bairro. Contudo, neste horário de forte insolação, o core foi amenizado em virtude da nebulosidade. Alcançando, portanto, moderada e fraca intensidade, respectivamente, na Rua Barão de Copacanema (Ponto 8 - UP13) e Av. Santa Cruz (Ponto 6) (favorecidos pelo intenso fluxo de veículos automotores e baixa umidade - UP13). Na Estrada da Água Branca (Ponto 5 UP5) e Rua Araquém/Av. Brasil (Ponto 4 - UP13), por serem espaços cujos logradouros são mais largos, o acúmulo de energia se faz de maneira menos eficiente, resultando na materialização como núcleos frescos.

Às 17 horas (Figura 12), o gradiente térmico comportou-se da maneira supracitada acima. Contudo, destaca-se que durante a ocorrência do transeto houve pancadas de chuvas. $O$ core do ponto quente expressou-se na Av. Santa Cruz (Ponto 6 - UP13), de moderada intensidade, não ultrapassando 4,0 ${ }^{\circ} \mathrm{C}$. Em oposição, a área de frescor configurou-se na Silva Cardoso (Ponto 11 - UP11).

Ainda que o sistema atmosférico regional atuante no dia do monitoramento de campo não seja favorável, foi possível reconhecer a variação temporo-espacial intrabairro dos espaços quentes (que variaram de fraca até muito forte magnitude $\left.\left(8,8^{\circ} \mathrm{C}\right)\right)$ e frios.

Importante ressaltar que a temperatura do ar sofreu influência de dois agentes: condições atmosféricas e combinação das formas físicas, biológicas e artificiais/função da paisagem intrabairro. Assim, compreendese a decrescente intensidade dos cores dos pontos quentes ao longo dos horários (dada a crescente nebulosidade e pluviosidade) e seu predomínio nos logradouros da área comercial e de serviço do bairro, como a Rua Barão de Copacanema (Ponto 8 - UP13) e Av. Santa Cruz (Ponto 6 - UP13) (Tabela 2): elevado fluxo de veículo, pouca arborização, calçadas e logradouros asfaltados, elevada densidade de construção, além de carregarem as características da unidade da paisagem 13 (vegetação não saudável, média de altura das edificação de $6 \mathrm{~m}$, orientação das encostas sentido norte e, segundo, a sondagem da TST de 2013 a 2019 , elevados registros $\left(30\right.$ a $\left.38^{\circ} \mathrm{C}\right)$ ). 


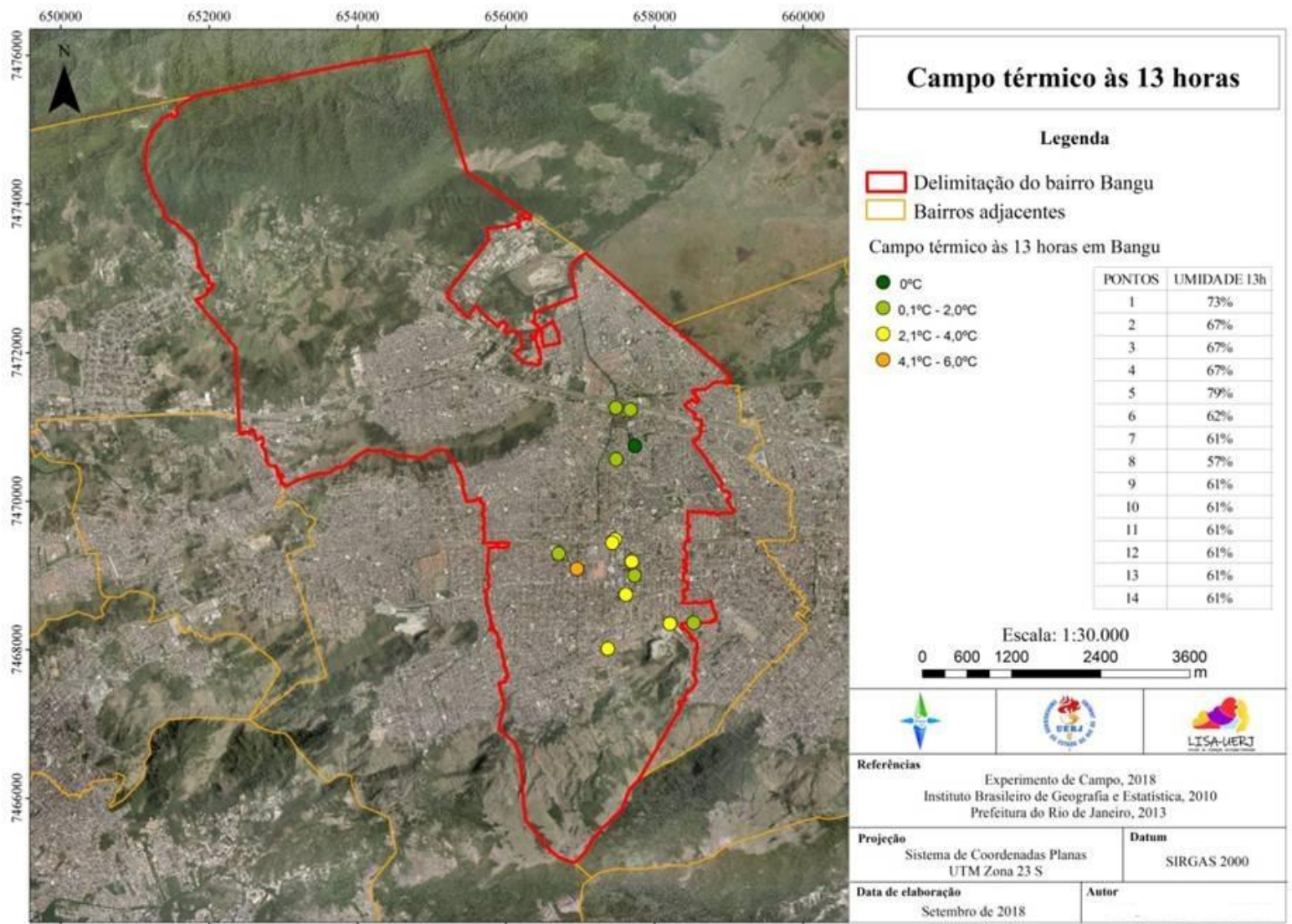

Figura 11: Campo térmico às 13 horas. Fonte: IBGE (2010); Prefeitura do RJ (2013); Experimento de Campo (2018).

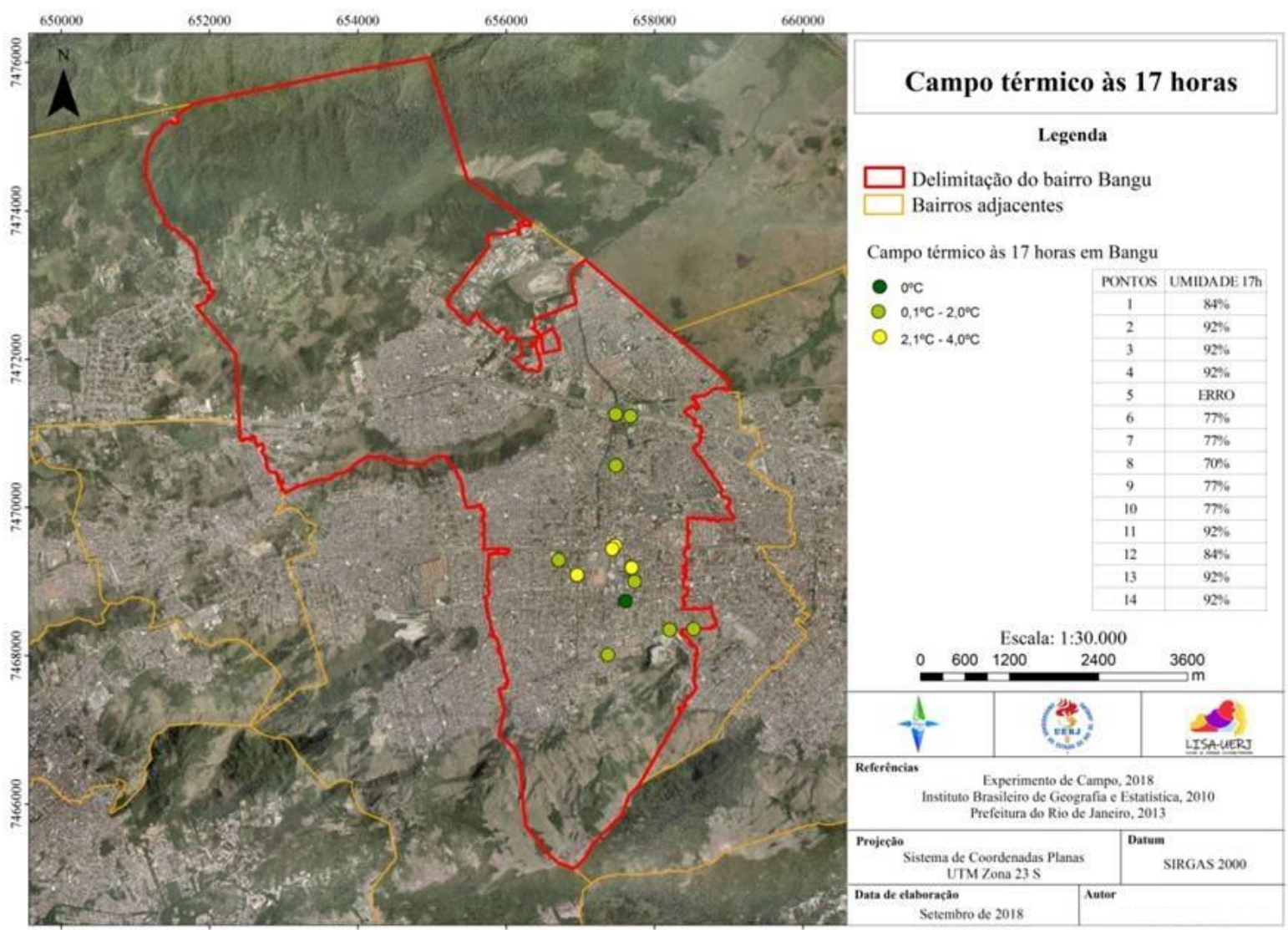

Figura 12: Campo térmico às 17 horas. Fonte: IBGE (2010); Prefeitura do RJ (2013); Experimento de Campo (2018). 
A Rua Padre Josino Tavares (Ponto 14), localizada na área residencial, também pertence a UP13. Contudo, sua posição como core quente nos dois primeiros transetos, deve-se possivelmente como já mencionado, aos materiais particulados da pedreira (Tabela 2). Bem como, os altos valores registrados de temperatura na Rua da Usina (Ponto 12 - UP13) e na Praça localizada na Rua Paris Vianna (Ponto 13 UP13).

Quanto aos pontos frescos, suas localizações na UP13 e UP5, mantiveram-se em áreas arborizadas e logradouros cujas geometrias largas facilitaram a dissipação do calor. Destaca-se aqui a Praça $1^{\circ}$ de Maio (Ponto 7 - UP13) como ponto fresco no horário das 9 horas, enfatizando que a mensuração foi realizada na sua porção sul, preservada da intervenção urbanística ocorrida no Rio Cidade II. Sua porção centro-norte, diferentemente, perdeu cobertura arbórea em detrimento da massa de concreto. A Rua Silva Cardoso, inserida na UP11, foi beneficiada pela área de cobertura vegetal. Segundo a TST, a UP11 apresentou os menores registros $\left(24^{\circ} \mathrm{C}\right.$ e $\left.28^{\circ} \mathrm{C}\right)$.

Outros resultados também foram encontrados ao analisar o ritmo térmico, ao longo dia, de cada ponto sondado (Tabela 3). Os pontos localizados na porção sul do transeto foram os que apresentaram maiores gradiente de temperatura, principalmente, a Rua Padre Josino Tavares (Ponto 14 - variação de 10,6C), Rua Silva Cardoso (Ponto 11 - variação $9,40^{\circ} \mathrm{C}$ ), Rua Barão de Copacanema (Ponto 8 variação $8,8^{\circ} \mathrm{C}$ ) e Rua da Usina (Ponto 12 - variação $8,8^{\circ} \mathrm{C}$ ).

Tabela 2: Quadro síntese das intensidades dos pontos em Bangu em episódio sazonal de inverno.

\begin{tabular}{llll}
\hline Horário & Mínimas & \multicolumn{2}{c}{ Locais com temperaturas expressivas } \\
& \multicolumn{1}{c}{ Máximas } & Diferença térmica \\
\hline $09: 00$ & P7 - Praça $1^{\circ}$ de Maio $\left(25,8^{\circ} \mathrm{C}\right)$ & $\begin{array}{l}\text { P14 - Rua Padre Josino Tavares } \\
\left(31,0^{\circ} \mathrm{C}\right)\end{array}$ & $5,2^{\circ} \mathrm{C}$ \\
& & $\begin{array}{l}\text { P14 - Rua Padre Josino Tavares } \\
\text { 11:00 }\end{array}$ & $8,8^{\circ} \mathrm{C}$ \\
& P2 - Av. Ministro Ary Franco/Estrada da & $\left(33,8^{\circ} \mathrm{C}\right)$ & \\
$13: 00$ & Água Branca $\left(25,0^{\circ} \mathrm{C}\right)$ & P8 - Rua Barão de Copacanema & $5,0^{\circ} \mathrm{C}$ \\
& P5 - Estrada da Água Branca $\left(28,6^{\circ} \mathrm{C}\right)$ & $\left(33,6^{\circ} \mathrm{C}\right)$ & \\
$15: 00$ & P4 - Rua Araquém/Av. Brasil $\left(23,2^{\circ} \mathrm{C}\right)$ & P6 - Av. Santa Cruz $\left(27,2^{\circ} \mathrm{C}\right)$ & $4,0^{\circ} \mathrm{C}$ \\
$17: 00$ & P11 - Rua Silva Cardoso $\left(22,6^{\circ} \mathrm{C}\right)$ & P6 - Av. Santa Cruz $\left(25,6^{\circ} \mathrm{C}\right)$ & $3,0^{\circ} \mathrm{C}$ \\
& & & \\
\hline
\end{tabular}

Tabela 3: Quadro síntese das intensidades dos pontos

\begin{tabular}{cccc}
\hline Pontos & Temp. $\max \left({ }^{\circ} \mathbf{C}\right)$ & Temp. mín $\left({ }^{\circ} \mathbf{C}\right)$ & $\triangle^{\circ} \mathbf{C}$ \\
\hline 1 & 33.00 & 24.80 & 8.20 \\
2 & 29.80 & 24.20 & 5.60 \\
3 & 30.20 & 23.40 & 6.80 \\
4 & 30.00 & 23.20 & 6.80 \\
5 & 30.00 & 24.40 & 5.60 \\
6 & 32.20 & 25.60 & 6.60 \\
7 & 30.60 & 24.40 & 6.20 \\
8 & 33.60 & 24.80 & 8.80 \\
9 & 32.20 & 25.20 & 7.00 \\
10 & 31.00 & 23.60 & 7.40 \\
11 & 32.00 & 22.60 & 9.40 \\
12 & 32.80 & 24.00 & 8.80 \\
13 & 32.00 & 24.40 & 7.60 \\
14 & 33.80 & 23.20 & 10.60 \\
\hline
\end{tabular}

Baseado em Brandão (1996) e nos resultados da Tabela 3, observa-se, de forma decisiva, a importância da dinâmica de brisas e da orografia do bairro para explicar os gradientes de variação de temperatura ao longo do dia; ao passo que os pontos centrais, cujas características urbanísticas limitam a circulação do ar e otimizam o armazenamento de calor também auxiliam no fenômeno. Finalmente, deve se considerar ainda a condição sinótica atuante, limitadora do fluxo energético local. 


\section{Considerações finais}

A pesquisa voltou-se a análise do comportamento térmico em Bangu, relacionando o padrão espacial da superfície terrestre e temperatura do ar às formas físicas, biológicas e antrópicas das unidades da paisagem do bairro. De fato, houve convergências entre os resultados in situ e os orbitais, que direcionaram os espaços verdes e logradouros largos das unidades da paisagem às temperaturas amenas e/ou pontos frios. Por outro lado, as UPs com áreas de comércio e serviços, logradouros estreitos, fluxo de veículos e pouca arborização às temperaturas mais altas e/ou pontos quentes. Na UP13 a TST variou de $30^{\circ} \mathrm{C}$ a $38^{\circ} \mathrm{C}$, manifestando-se na área residencial de seu espaço o core máximo de $8,8^{\circ} \mathrm{C}$.

Em face dos resultados, é possível reconhecer que Bangu expõem problemáticas típicas direcionadas à forma de construção social de seu espaço. Projetos como Rio Cidade não atenderam as reais necessidades, não colocando em pauta questões ambientais (arborização, clima, poluição, enchentes e inundações, dentre outros) nem sociais, podendo trazer rebatimentos sobre a saúde. Em virtude do exposto, pode-se pensar em recomendações e medidas. Ei-las:

Ao Poder Público: a) elaboração de Planos diretores voltados à especificidade do bairro e não por macrozoneamento; b) políticas públicas de ordenamento e planejamento territorial adequado às realidades topoclimáticas do bairro; c) consideração das formas físicas e biológica no ordenamento e planejamento urbano; d) fiscalização e reflorestamento da serra de Bangu e conservação da serra do Mendanha; e) implantação da arborização urbana e monitoramento da saúde vegetacional; f) programas de educação ambiental formais e informais, que aproximem os moradores com a conservação dos elementos naturais; $\mathrm{g}$ ) manutenção do sistema de climatização implantado no centro comercial e de serviços.

Aos moradores: a) valorização e conservação dos espaços verdes; constituição de jardins verticais; b) pintar as construções com tintas de coloração clara para maior reflexão de energia e menor conservação do calor; c) alocar janelas nas construções em lados opostos, possibilitando a ventilação cruzada; d) instalação de telhados verdes e brancos; e) diminuição da taxa de impermeabilização dos quintais.

\section{Referências bibliográficas}

AMORIM, M. C. C. T. Clima urbano: concepções teóricas, metodologias, aplicações e perspectivas. Rancharia. In: XVI SIMPÓSIO BRASILEIRO DE GEOGRAFIA FÍSICA APLICADA, 2015, Teresina. Anais... Teresina: UFPI. 2015.

AYOADE, J. O. Introdução a climatologia para os trópicos. Tradução: Maria Juraci dos Santos. $4^{a}$ ed., Rio de Janeiro: Bertrand Brasil; 1996.

BARSI, J. A., BACKER, J. L.; SCHOTT, J. R. An Atmospheric correction parameter calculator for a single thermal. Proc. IEEE IGARSS, Toulouse, France, 3014-3016, 2003. DOI 0-7803-7930-6

BARSI, J. A. et al. Validation of a web-based atmospheric correction tool for single thermal band instruments. Proceedings, SPIE, v. 5882. Paper 58820E. Bellingham, WA. 2005.

BERTRAND, G. Paisagem e geografia física global - esboço metodológico. Tradução: Olga Cruz. R.RA'EGA, Curitiba, v. 8, 141-152, 2004.

BRANDÃO. A. M. P. M. O clima urbano da cidade do Rio de Janeiro. 1996. 362p. Tese (Doutorado em Geografia). Departamento de Geografia/FFLHC, Universidade de São Paulo, 1996.

BRANDÃO, A M. P. M.; LUCENA. A. J. O campo térmico na área central do Rio de Janeiro em duas situações de primavera (1997 e 1998). In: IV Simpósio Brasileiro de Climatologia Geográfica, 2000, Rio de Janeiro. Anais... Rio de Janeiro: UFRJ. 2000.

DANNI-OLIVEIRA, I. M. Aspectos conceituais do sistema clima urbano: uma breve revisão bibliográfica sobre as ilhas de calor. Caderno de Geociências, Rio de Janeiro, v. 15, 13-26, 1995.

FARIAS, H. S.; BRANDÃO. A. M. P. M. O campo térmico como indicador de qualidade ambiental para políticas públicas: estudo de caso no bairro Maracanã/RJ. In: III ENCONTRO DAS ANPPAS, 2006, Brasília. Anais... Brasília: Centro de Convenções Israel Pinheiro, 2006. 
FRANÇA, D. A.; BRANDÃO. A. M. P. M. O bairro Méier (RJ). O campo térmico e a percepção ambiental dos moradores em episódio de verão e de inverno. In: IV Simpósio Brasileiro de Climatologia Geográfica, 2000, Rio de Janeiro. Anais... Rio de Janeiro: UFRJ. 2000.

GARTLAND, L. Ilhas de calor: como mitigar zonas de calor em áreas urbanas. Tradução: Silva Helena Gonçalves. São Paulo: Oficina de Textos; 2010.

INSTITUTO BRASILEIRO DE GEOGRAFIA E ESTATÍSTICA. Sinopse por setores. Disponível em: <https://censo2010.ibge.gov.br/>.

LEMOS, L. O; OSCAR JÚNIOR, A. C. Proposta metodológica para seleção de áreas amostrais em estudos do subcanal termodinâmico: estudo de caso das ilhas de calor no bairro Bangu (RJ). In: XII SIMPÓSIO BRASILEIRO DE CLIMATOLOGIA GEOGRÁFICA, 2016, Goiânia. Anais... Goiânia: UFG/ABClima. 2016.

LUCENA, A. J.; BRANDÃO. A. M. P. M. O campo térmico em Bangu em duas situações sazonais de verão e outono. In: IV SIMPÓSIO BRASILEIRO DE CLIMATOLOGIA GEOGRÁFICA, 2000, Rio de Janeiro. Anais... Rio de Janeiro: UFRJ. 2000.

LUCENA, A. J. O clima de Bangu no contexto do Clima Urbano da cidade do Rio de Janeiro. 2002. 91 p. Monografia (Bacharelado em Geografia). Instituto de Geociência, Departamento de Geografia, Universidade Federal do Rio de Janeiro, Rio de Janeiro, 2002.

MALHEIROS, T. S.; BRANDÃO. A. M. P. M. O bairro de Copacabana (RJ): o campo térmico e a percepção ambiental da população em uma situação de verão e de inverno. In: IV SIMPÓSIO BRASILEIRO DE CLIMATOLOGIA GEOGRÁFICA, 2000, Rio de Janeiro. Anais... Rio de Janeiro: UFRJ. 2000.

MONTEIRO, C. A. de F. Teoria e Clima Urbano. 1976. São Paulo: Série Teses e Monografia. n. 25, 181 p. Tese (Doutorado em Geografia) Instituto de Geografia/FFLHC, Universidade de São Paulo, 1976.

MONTEIRO, C. A. de F. Adentrar a cidade para tomar-lhe a temperatura. Revista Geosul, Florianópolis, v.5, n.9, 61-79, 1990.

MONTEIRO, C. A. de F. Teoria e clima urbano. In: MENDOÇA, F.; MONTEIRO, C. A. de F (orgs). Clima urbano. 2. Ed., São Paulo: Contexo, 2015. p. 9-68.

NASA/GSFC - NASA's Goddard Space Flight Center - Atmospheric Correction Parameter Calculator. Disponível em: <https://atmcorr.gsfc.nasa.gov/>.

OSCAR JÚNIOR, A. C. S.; BRANDÃO. A. M. P. M. O sistema clima urbano da ilha do fundão (RJ): subsídio para o planejamento urbano. Revista Brasileira de Geografia Física, Recife, v. 8, n. 1, 113-127, 2015.

PAZERA JÚNIOR, E. A ilha de calor da cidade: fatores e atributos. Boletim Geográfico, Rio de Janeiro, v. 34, n. 249, 51-57, 1976.

PEREIRA, P. V. SANTOS.; BRANDÃO. A. M. P. M. Urbanização e derivações no clima local: estudo de caso no bairro Penha. In: VIII SIMPÓSIO BRASILEIRO DE CLIMATOLOGIA GEOGRÁFICA, 2008, Alto Caparaó. Anais... Alto Caparaó: UFU/ABClima. 2008.

ROUSE, J. W.; HAAS, R. H.; SCHELL, J. A.; DEERING, D. W. Monitoring vegetation systems in the great plains with ERTS. In: EARTH RESOURCES TECNOLOGY SATELLITE-1 SYMPOSIUM, 3, Proceedings. Washington, v.1, 1973. p. 309-317.

SANTOS,M. A Natureza do Espaço. Técnica e Tempo. Razão e Emoção. 2.ed. São Paulo: Editora Hucitec, 1997. 
SIURB - Sistema Municipal de Informações Urbanas. Dados geográficos abertos da Prefeitura da cidade do Rio de Janeiro. Disponível em: <http://portalgeopcrj.opendata.arcgis.com/datasets/1f47aafdbe8c4d66b7da4a2f1f395eb3_7>.

USGS - United States Geological Survey - Earth Explorer. Disponível em: < https://earthexplorer.usgs.gov/>.

VAN DE GRIEND, A. A.; OWE, M. On the relationship between thermal emissivity and the normalized difference vegetation index for natural surfaces. International Journal of Remote Sensing, v. 14, 11191131, 1993. DOI: $\underline{10.1080 / 01431169308904400}$

ZHANG, Y. Land surface temperature retrieval from CBERS-02 IRMSS thermal infrared data and its applications in quantitative analysis of urban heat island effect. J. Remote Sens. 10, 789-797. 2006. DOI: $10.12691 /$ jap-4-1-3

(1) 